\title{
Keberkesanan Kaedah Model Skema Bagi Meningkatkan Kefahaman dan Minat Pelajar Terhadap Cerpen Bahasa Melayu
}

\author{
SUBADRAH NAIR \\ Universiti Sains Malaysia \\ RAJESWARI ARUMUGAM \\ Sekolah Menengah Convent Butterworth
}

\begin{abstract}
Abstrak: Artikel ini membincangkan teori skema dan kesan penggunaan model skema dalam pengajaran cerpen (KOMSAS) Bahasa Melayu. Pengkaji-pengkaji teori skema menegaskan skema atau pengetahuan latar dapat membantu meningkatkan kefahaman bacaan pelajar. Suatu kajian kuasi eksperimen telah dijalankan untuk mengenal pasti kesan penggunaan model skema terhadap pencapaian kefahaman pelajar dan minat pelajar terhadap cerpen (KOMSAS). Dapatan kajian tersebut menunjukkan pengajaran dengan menggunakan model skema dapat meningkatkan pencapaian pelajar secara signifikan bagi soalan tentang persoalan, soalan tentang perwatakan, soalan tentang latar masyarakat dan soalan tentang gaya bahasa berbanding dengan pencapaian pelajar yang diajar dengan menggunakan pendekatan tradisional. Selain itu, didapati minat pelajar terhadap cerpen turut meningkat secara signifikan setelah diajar dengan menggunakan model skema.
\end{abstract}

Abstract: This article discusses schema theory and the effect of utilizing the schematic model in the teaching of short stories (literature components) in the Malay Language. Proponents of schema theory have stressed the role of schema or prior knowledge in assisting and enhancing students' reading comprehension. A quasi experimental study was carried out to identify the effect of using a schematic model on the achievement of students in comprehending short stories and their interest towards reading short stories. The findings indicate that the use of the schematic model significantly enhanced students' achievement in answering questions related to issues, characterization, social settings and language styles compared with the traditional approach. Interest towards reading short stories was also significantly enhanced. 


\section{PENGENALAN}

Komponen Kesusasteraan Melayu (KOMSAS) telah dilaksanakan di semua sekolah menengah (Bagi Tingkatan Satu hingga ke Tingkatan Empat) mulai tahun 2000. Pada tahun 2001, komponen ini mula diuji dalam mata pelajaran Bahasa Melayu pada peringkat Sijil Pelajaran Malaysia. Pelaksanaan komponen ini bukanlah sesuatu yang baru tetapi merupakan lanjutan daripada unsur sastera dalam mata pelajaran Bahasa Melayu yang telah diperkenalkan pada tahun 1984.

Genre sastera yang diketengahkan dalam KOMSAS ialah novel, cerpen, drama, prosa tradisional dan sajak. Aspek-aspek sastera yang perlu dipelajari oleh pelajar pula ialah sinopsis, tema, persoalan, mesej, plot, watak dan perwatakan, nilai-nilai kemanusiaan dan gaya bahasa (Kementerian Pendidikan Malaysia, 1999). Antara objektif utama pengajaran KOMSAS di sekolah ialah untuk meningkatkan minat membaca di kalangan pelajar, mengenali, menghayati dan menghargai karya sastera; menilai dan mengkritik karya sastera.

Pelaksanaan KOMSAS di sekolah-sekolah dapat memartabatkan kesusasteraan Melayu kerana sebelum ini kesusasteraan Melayu hanya dipelajari oleh segolongan kecil pelajar daripada aliran Kemanusiaan. Selepas pengenalan KOMSAS setiap pelajar diwajibkan mempelajari kesusasteraan Melayu. Sejajar dengan hasrat perlaksanaan KOMSAS ini secara langsung memberi peluang kepada setiap pelajar mempelajari khazanah kesusasteraan Melayu di sekolah.

Menurut Rahman Shaari (1990) terdapat dua sebab kesusasteraan Melayu diajar dalam mata pelajaran Bahasa Melayu. Pertama, bahan kesusasteraan menggunakan bahasa yang menarik terutama dari sudut keindahannya. Kedua, bahan kesusasteraan memiliki daya tarikan yang dapat menimbulkan minat pelajar untuk membacanya dan daya tarikan ini timbul daripada sifat karya kesusasteraan yang selalunya memiliki ciri-ciri menghibur.

Walau bagaimanapun, sebelum seseorang pelajar dapat menganalisis, menghargai dan menghayati sesuatu karya sastera, pelajar tersebut memerlukan bantuan dan bimbingan untuk memahami karya tersebut dengan baik. Saedah Siraj (1992) turut menegaskan pembaca perlu mempelajari kemahiran-kemahiran tertentu untuk memahami dan menghayati karya sastera yang dibacanya.

Izzah Abdul Aziz (2000) menjelaskan dalam pembelajaran KOMSAS pelajar harus memahami teks yang dibacanya dan seterusnya 
dapat menilai dan mengkritik karya tersebut. Ini adalah kerana lazimnya dalam sesuatu teks, pengarang mengutarakan mesej yang ingin disampaikannya secara tersirat iaitu melalui tema dan persoalan, gambaran perwatakan, latar masyarakat dan bahasa yang digunakannya. Kenyataan tersebut disokong oleh Lazar (1993) yang menegaskan pelajar perlu membuat interpretasi untuk memahami urutan plot, watak dan perwatakan, perbendaharaan kata dan seterusnya persoalan-persoalan yang ingin diutarakan oleh pengarang.

Menurut Durokhman Mohd Basri (2001), pada masa sekarang modal utama dalam proses pengajaran dan pembelajaran KOMSAS di sekolah-sekolah ialah buku teks berbentuk novel, drama, puisi dan cerpen; sementara guru menggunakan strategi pengajaran yang menyuruh pelajar membaca di rumah atau di kelas. Kemudian perbincangan diadakan dalam kelas. Seterusnya guru akan memberi nota tentang aspek yang dikaji (tema dan persoalan, perwatakan, latar masyarakat dan gaya bahasa) pada hari tersebut. Keadaan yang sedemikian menyebabkan pembelajaran KOMSAS menjadi hambar dan pelajar kurang berminat terhadap pembelajaran KOMSAS. Laporan Peperiksaan Sijil Pelajaran Malaysia (Lembaga Peperiksaan Malaysia, 2001) juga menegaskan calon tidak dapat menjawab soalan-soalan yang berkaitan dengan KOMSAS dengan baik. Laporan tersebut turut menyarankan agar guru-guru menitikberatkan aspek watak dan perwatakan, persoalan dan latar masyarakat dalam pengajaran KOMSAS. Guru-guru juga disarankan agar mempelbagai kaedah dan teknik pengajaran dan pembelajaran bagi meningkatkan pemahaman pelajar terhadap KOMSAS.

Aspek pedagogi iaitu pendekatan yang digunakan dalam pengajaran KOMSAS perlu diberikan penekanan oleh guru yang mengajar Bahasa Melayu bagi meningkatkan pemahaman pelajar terhadap teks yang dikaji. Malangnya dalam Huraian Sukatan Pelajaran (Kementerian Pendidikan Malaysia, 2001) aspek pedagogi iaitu pendekatan mengajar KOMSAS langsung tidak diberikan penekanan.

Pengkaji teori skema antaranya Driscoll (1994), Rumelhart (1977), Spiro (1980), Chiang dan Dunkel (1992), Anderson (2000) dan Brynes (2001) menjelaskan skema atau pengetahuan latar membantu pelajar dalam proses kefahaman bacaan. Skema ialah pengetahuan yang dibina dalam struktur kognitif seseorang. Seseorang pembaca menghubung kaitkan maklumat yang dibacanya dengan skema yang relevan yang terdapat dalam struktur kognitifnya untuk memahami maksud penulis. 
Spiro (1980) menegaskan skemata sahaja tidak mencukupi untuk membantu kefahaman pembaca. Pembaca harus tahu mengaktifkan skema yang tepat agar dia dapat memahami apa yang dibacanya. Kesan skema dalam pengajaran KOMSAS perlu dikaji untuk mengenal pasti sama ada pendekatan skema dapat membantu pelajar dalam pemahaman KOMSAS.

\section{Sejarah Perkembangan Teori Skema}

Konsep skema telah wujud sejak tahun 1781 apabila Kant (1963) menegaskan setiap maklumat, konsep baru dan idea baru hanya bermakna pada seseorang apabila individu tersebut menghubungkaitkan maklumat yang diperolehnya dengan pengetahuan yang sedia ada padanya. Sungguhpun Kant tidak menggunakan istilah skema dalam perbincangannya tetapi sebenarnya beliau telah meletakkan asas bagi teori skema. Istilah skema mula-mula digunakan oleh seorang ahli psikologi bernama Bartlett (1932) yang mendapati pembaca menggunakan pengetahuan latar dalam proses memahami teks yang dibaca oleh mereka. Kajian Bartlett juga membuktikan skema bersifat aktif dan sentiasa berubah.

Pada awal abad kedua puluh, teori skema mendapat perhatian ahli-ahli psikologi aliran Gestalt. Pada tahun 1960an teori skema mendapat perhatian pengkaji bidang pembelajaran contohnya Ausubel (1963). Menjelang tahun 1970an teori skema mendapat perhatian pengkaji-pengkaji sains kognitif contohnya Schank dan Abelson (1977). Mulai tahun 1990an teori skema mempengaruhi perkembangan dalam bidang komputer (Chervenick, 1992). Kajian Allman (1988) yang disebut dalam Chervenick (1992) menyokong teori skema dan menghuraikan cara skema diaktifkan. Menurut Allman, kemampuan otak manusia jauh lebih ungggul daripada komputer yang paling canggih. Neuron dalam rangkaian otak manusia berhubung antara satu dengan lain untuk memadankan maklumat yang diperoleh dengan pengetahuan yang sedia ada dalam ingatan. Dalam proses ini bentuk maklumat yang menyerupai maklumat yang disimpan dalam ingatan seseorang akan diperkukuh dan maklumat yang tidak berkaitan diketepikan; dengan cara ini maklumat baru yang dibaca oleh seseorang itu akan difahaminya.

Menurut Rumelhart (1980) skemata ialah blok binaan kognisi (building blocks of cognition) yang meliputi semua bidang ilmu, aksi, pengalaman, perasaan dan peristiwa. Pengetahuan ini 
dibungkus dalam unit-unit tertentu dan disusun secara hirarki dan disimpan dalam ingatan manusia. Setiap skema mempunyai jaringan yang saling berkait. Skema menyediakan rangka yang membolehkan pembaca mengorganisasi maklumat dengan berkesan. Skema bersifat aktif, sentiasa berubah dan berkembang selaras dengan maklumat baru yang diperoleh pembaca. Menurut Anderson (1985) skema memainkan peranan yang sangat penting dalam proses kefahaman bacaan seseorang terutama skema budaya.

\section{Cara-cara Skema Membantu Dalam Pembelajaran}

Skemata (istilah jamak bagi skema) membantu seseorang dalam proses pembelajaran melalui lima cara:

Pertama, pembaca menggunakan pengetahuan yang terkumpul dalam mindanya untuk memahami teks yamg dibacanya. Rumelhart dan Norman (1978) menggunakan istilah 'accretion' bagi pembelajaran dengan cara ini. Kedua, pembaca membentuk skemata baru, iaitu jika pembaca tidak mempunyai skema tentang latar masyarakat subbandar dalam teks yang dibacanya, dia akan membentuk skemata baru berdasarkan skema latar masyarakat bandar dan luar bandar yang ada padanya untuk memahami latar masyarakat subbandar yang dibacanya (Subadrah, 2001). Ketiga, skemata yang ada pada seseorang mungkin berubah selaras dengan pengetahuan baru yang diperoleh atau pengalaman yang dialaminya. Menurut Rumelhart dan Norman (1978) pembelajaran dengan cara ini dikenali sebagai 'tuning' atau penalaan. Keempat, seandainya maklumat yang dibaca oleh seseorang itu baru, pembaca mungkin akan menggabungkan dua atau lebih skemata untuk memahami maklumat yang baru itu. Pembentukan skemata baru ini dikenali sebagai 'restructuring' oleh Rumelhart dan Norman (1978). Kelima, pembaca akan menggunakan analogi berdasarkan pengetahuan yang sedia ada untuk mendapatkan makna bagi maklumat yang dibacanya (Spiro, 1980; Gagne, Yekovich \& Yekovich, 1993).

Banyak kajian yang dilakukan di dalam negara dan di luar negara menunjukkan keberkesanan penggunaan skema dalam pengajaran dan pembelajaran. Kajian yang dilakukan oleh Singer dan Donlan (1982), Dimino, Gersten, Carnine, dan Blake (1990), Emery (1996), Webster (2001) dan Byrnes (2001) menunjukkan bahawa skema adalah faktor yang penting dalam mempengaruhi pemahaman bacaan pelajar. 
Jadual 1. Model Skema Yang Digunakan Dalam Pengajaran KOMSAS

TAHAP SATU: Guru mengemukakan model skema kepada pelajar iaitu skema isi tersurat, skema persoalan dan skema latar masyarakat/ skema perwatakan dan skema gaya bahasa.(Dalam satu pelajaran hanya dua skema yang diajar kepada pelajar).

- Guru menjelaskan tujuan pengajaran.

- Guru memberikan skema kepada pelajar iaitu skema persoalan dan skema latar masyarakat / skema perwatakan dan skema gaya bahasa.

- Guru memberikan penjelasan tentang skema yang di ajar.

- Guru memberikan contoh.

- Pengajaran dikaitkan dengan pengalaman dan pengetahuan pelajar.

TAHAP DUA: Guru memberikan petikan cerpen (KOMSAS Bahasa Melayu kepada pelajar.

- Pelajar merujuk cerpen yang dikaji

- Pelajar dikehendaki mencari maklumat dalam cerpen untuk menjawab soalan pada peringkat isi tersurat, persoalan dan latar masyarakat/isi tersurat, perwatakan dan gaya bahasa.(Dalam satu pelajaran hanya soalan tersurat dan soalan tentang dua jenis skema sabaja diberikan kepada pelajar)

- Pelajar dilatih menggunakan skema untuk mengorganisasikan maklumat bagi menjawab soalan pada peringkat isi tersurat dan isi tersirat (persoalan dan latar masyarakat / perwatakan dan gaya bahasa).

TAHAP TIGA: Pengukuhan Organisasi Kognitif \& Efektif

- Pelajar menjawab soalan-soalan pada peringkat tersurat dan tersirat dengan menyepadukan dan mengintegrasikan prinsip-prinsip skema yang dipelajari.

- Guru menggalakkan pelajar berfikir secara kritis dan kreatif untuk mendapatkan maklumat yang tersirat dalam petikan.

- Guru memberikan penjelasan

- Latihan bertulis

Pengkaji tempatan antaranya Safiah Osman (1987), Chai Moo Hong (1989), Thang Siew Meng (2001) dan Mahorani Yusoff (1989) turut menegaskan, skema atau pengetahuan latar dapat membantu pelajar memahami teks yang dibaca oleh mereka. Subadrah Nair (2001) telah menghasilkan modelskema sebagai satu alat pedagogi untuk mengajar kefahaman bacaan bahan sastera. Dapatan kajian tersebut menunjukkan pendekatan model skema dapat meningkatkan pencapaian subjek secara signifikan bagi soalan tentang tema dan persoalan, perwatakan dan 
gaya bahasa. Kajian Sathiapathi (2004) dan Sundee (2005) turut menjelaskan model skema dapat membantu pelajar dalam pemahaman bacaan bahan sastera.

\section{Model skema}

Dalam kajian ini, pengkaji menggunakan model skema yang dihasilkan oleh Subadrah (2001) bagi pengajaran cerpen. Model ini berasaskan teori skema dan model pengurusan awal Ausubel (1963). Model pembelajaran Ausubel (1963) bersifat umum dan menyediakan struktur kognitif kepada pelajar untuk memahami bahan bacaan, bahan kuliah dan bahan media. Model skema yang dihasilkan oleh Subadrah (2001) ialah khusus bagi mengajar bahan sastera. Mengikut model ini, skema pelajar tentang cerpen (isi tersurat, tema dan persoalan, perwatakan, latar masyarakat dan gaya bahasa) akan dibina secara terancang dalam struktur kognitif pelajar selama enam minggu. Selama enam minggu pelajar dilatih mengaktifkan skema yang relevan bagi memahami aspek isi tersurat, persoalan, perwatakan, latar masyarakat dan gaya bahasa dalam cerpen yang dibaca oleh mereka.

Proses pengajaran dan pembelajaran yang menggunakan model skema ini mempunyai tiga tahap penting dan dijelaskan dalam Jadual 1. Pada Tahap Satu, guru mengemukakan skema sastera kepada pelajar secara terancang. Pada Tahap Dua pelajar dilatih mengaktifkan skema sastera yang dipelajari untuk mengorganisasikan maklumat daripada cerpen. Tahap Ketiga merupakan aktiviti pengukuhan organisasi kognitif dan efektif iaitu pelajar dikehendaki menyepadu dan mengintergrasi prinsip-prinsip skema sastera untuk menjawab soalan-soalan kefahaman cerpen. Seterusnya pada Tahap Ketiga juga dijalankan aktiviti pengukuhan skema (latihan bertulis dan pelajar diminta merumus skema yang dipelajari pada hari tersebut). 
Jadual 2. Rangka Rancangan Pelajaran Yang Menggunakan Model Pengajaran Skema

\begin{tabular}{ll}
\hline $\begin{array}{l}\text { Set Induksi } \\
(5 \text { minit })\end{array}$ & $\begin{array}{l}\text { Guru memberikan bahan rangsangan kepada } \\
\text { pelajar. }\end{array}$ \\
\hline $\begin{array}{l}\text { Langkah I } \\
(15 \text { minit })\end{array}$ & $\begin{array}{l}\text { Guru memberikan skema (pengetahuan sastera) } \\
\text { kepada pelajar dan menjelaskan kepada pelajar } \\
\text { dengan memberikan contoh (rujuk lampiran A). }\end{array}$ \\
\hline
\end{tabular}

Langkah II Guru memberikan petikan (bahan) sastera kepada (5 minit) pelajar untuk dibaca dan difahami.

Langkah III Guru menyuruh pelajar menggunakan skema (15 minit) sebagai asas untuk memahami maklumat yang tersurat dan tersirat dalam petikan dan mencari jawapan bagi soalan tersurat/eksplisit dan implisit. Bagi soalan tersurat/eksplisit jawapannya terdapat dalam permukaan teks. Soalan implisit pula adalah soalan tentang persoalan dan latar masyarakat/ soalan tentang perwatakan dan gaya bahasa. Aktiviti ini dijalankan secara kumpulan (rujuk jadual 3.4).

Langkah IV Guru menyoal pelajar dan pelajar menjawab soalan (15 minit) kefahaman secara lisan. Guru menggalakkan pelajar mendapatkan maklumat tersirat untuk menjawab soalan implisit dengan menggunakan skema. Guru juga memberikan penjelasan apabila perlu.

Langkah $\mathrm{V}$ (20minit)

Latihan menjawab soalan-soalan pemahaman secara bertulis dalam buku latihan.

Penutup Pelajar diminta merumuskan skema yang telah (5 minit) dipelajari pada hari itu.

*Aktiviti dalam Tahap Satu dijalankan dalam Langkah I.

*Aktiviti dalam Tahap Dua dijalankan dalam Langkah II dan Langkah III.

*Aktiviti dalam Tahap Tiga dijalankan dalam Langkah IV , V dan Penutup. 


\section{Objektif kajian}

Objektif kajian ini ialah untuk memastikan sama ada penggunaan model skema dalam pengajaran cerpen (KOMSAS Bahasa Melayu) dapat meningkatkan pencapaian subjek Kumpulan Eksperimen secara signifikan berbanding dengan pencapaian Kumpulan Kawalan yang diajar dengan menggunakan pendekatan tradisional. Selain itu, kajian ini juga bertujuan untuk mengenal pasti sama ada minat subjek kumpulan Eksperimen terhadap cerpen meningkat secara signifikan atau tidak selepas pengajaran dengan menggunakan model skema.

\section{Hipotesis Kajian}

Tujuh hipotesis nul diuji pada paras signifikan 0.05. Kajian ini menguji sama ada terdapat perbezaan yang signifikan antara kumpulan eksperimen dan kumpulan kawalan dari segi:

1. min pencapaian bagi keseluruhan soalan pemahaman cerpen.

2. min pencapaian bagi soalan tersurat.

3. min pencapaian bagi soalan tentang persoalan.

4. min pencapaian bagi soalan tentang perwatakan.

5. min pencapaian bagi soalan tentang latar masyarakat.

6. min pencapaian bagi soalan tentang gaya bahasa.

7. minat terhadap cerpen sebelum dan selepas pengajaran dengan menggunakan model skema.

\section{METODOLOGI}

\section{Sampel kajian}

Sampel kajian ini terdiri daripada 64 orang pelajar perempuan Tingkatan Empat aliran Perdagangan dari dua buah sekolah menengah perempuan di Pulau Pinang. Subjek dari sekolah A dipilih sebagai Kumpulan Eksperimen dan subjek dari sekolah B dipilih sebagai Kumpulan Kawalan. Setiap sekolah mewakili satu kumpulan kajian agar pengajaran yang diberikan kepada satu kumpulan tidak mempengaruhi kumpulan lain.

Subjek daripada kedua-dua kumpulan merupakan pelajar yang mempunyai tahap pencapaian yang sederhana dan hampir sama dalam mata pelajaran Bahasa Melayu pada peringkat Penilaian Menengah Rendah (PMR). Gred pencapaian subjek dijelaskan dalam Jadual 3. 
Jadual 3. Pencapaian dalam Mata Pelajaran Bahasa Melayu PMR (2002)

\begin{tabular}{lcccccc}
\hline Kumpulan /gred & A & B & C & D & E & Jumlah \\
\hline Eksperimen & - & 17 & 13 & 2 & - & 32 \\
& & $(53.1)$ & $(40.6)$ & $(6.3)$ & $(0)$ & $(100)$ \\
\hline Kawalan & - & 15 & 13 & 4 & - & 36 \\
& & $(46.9)$ & $(40.6)$ & $(12.5)$ & $(0)$ & $(100)$ \\
\hline
\end{tabular}

*Angka tanpa kurungan menunjukkan kekerapan pelajar

*Angka di dalam kurungan menunjukkan peratus pelajar

Rasional pemilihan sampel kajian ialah kerana pelajar daripada kedua-dua buah sekolah ini mempunyai beberapa ciri yang sama iaitu:

i. pelajarnya terdiri daripada tiga kaum (Melayu, Cina dan India)

ii. kedua-dua sekolah terletak di kawasan bandar

iii. subjek terdiri daripada pelajar perempuan aliran Perdagangan iv. subjek mempunyai tahap pencapaian yang sederhana bagi mata pelajaran Bahasa Melayu dalam Peperiksaan PMR 2002

\section{Reka bentuk kajian}

Kajian ini menggunakan reka bentuk kuasi eksperimen. Reka bentuk kajian dijelaskan dalan Jadual 4.

Jadual 4. Reka Bentuk Kajian

$\begin{array}{rll}\text { Kumpulan Eksperimen Praujian dan } & X^{*} \quad \begin{array}{l}\text { Pascaujian dan } \\ \text { Soal selidik }\end{array} & \text { Soal selidik }\end{array}$

Kumpulan Kawalan Praujian $Y^{*}$ Pascaujian

*X: Pengajaran menggunakan Model Skema selama enam minggu

*Y: Pengajaran menggunakan pendekatan tradisional selama enam minggu

Pembolehubah bebas dalam kajian ini ialah pendekatan pengajaran yang digunakan bagi Kumpulan Eksperimen dan Kumpulan Kawalan. Kumpulan Eksperimen diajar cerpen 
(KOMSAS Bahasa Melayu) dengan menggunakan model skema selama enam minggu dan Kumpulan Kawalan pula diajar dengan menggunakan pendekatan tradisional.

Kajian ini dijalankan selama lapan minggu. Pada minggu pertama subjek Kumpulan Eksperimen dan Kumpulan Kawalan diberikan Praujian yang terdiri daripada soalan tersurat, soalan tentang persoalan, soalan tentang perwatakan, soalan tentang latar masyarakat dan soalan tentang gaya bahasa. Selepas Praujian hanya subjek Kumpulan Eksperimen diberikan soal selidik untuk memastikan minat mereka terhadap pembelajaran cerpen (KOMSAS). Mulai minggu kedua hingga minggu ketujuh (selama enam minggu) subjek Kumpulan Eksperimen dan Kumpulan Kawalan diberikan pengajaran selama enam minggu. Kumpulan Eksperimen diajar dengan menggunakan model skema dan Kumpulan Kawalan pula diajar dengan menggunakan pendekatan tradisional. Setiap minggu subjek diajar sekali seminggu dan setiap kali dua waktu pengajaran (80 minit).

Sebelum pengajaran dimulakan, guru mata pelajaran Bahasa Melayu yang mengajar cerpen (KOMSAS) untuk Kumpulan Eksperimen telah diberi taklimat dan dilatih oleh pengkaji tentang pengajaran dengan menggunakan model skema. Pengkaji juga memberikan rancangan pengajaran yang lengkap (berasaskan model skema) untuk enam minggu kepada guru yang mengajar Kumpulan Eksperimen. Di samping itu, pengkaji juga membekalkan guru yang mengajar Kumpulan Eksperimen dengan alat bantu mengajar untuk digunakan dalam aktiviti pengajaran skema secara terancang. Setiap pengajaran guru daripada Kumpulan Eksperimen telah dicerap oleh pengkaji bagi memastikan guru dapat mengajar setiap langkah pengajaran berasaskan model skema yang disediakan oleh pengkaji. Pengajaran Kumpulan Kawalan telah dicerap oleh pengkaji hanya sebanyak tiga kali dan pengkaji mendapati pengajaran Kumpulan Kawalan adalah lebih berpusatkan guru iaitu guru banyak memberikan penerangan dan dan pelajar mencatat nota yang diberikan oleh guru (rujuk jadual 5).

Bagi subjek Kumpulan Kawalan pula selepas Praujian, subjek diajar cerpen (KOMSAS) selama enam minggu oleh guru mata pelajaran Bahasa Melayu kelas tersebut. Pengkaji tidak memberikan rancangan pengajaran yang menggunakan model skema kepada guru tersebut. Guru daripada Kumpulan Kawalan hanya diberikan objektif pengajaran untuk selama enam minggu oleh pengkaji sama seperti guru daripada Kumpulan Eksperimen. Berbeza dengan guru 
Jadual 5. Perbandingan Model Skema Pendekatan Tradisional

\begin{tabular}{|c|c|}
\hline $\begin{array}{l}\text { Kumpulan Eksperimen } \\
\text { (model skema) }\end{array}$ & $\begin{array}{l}\text { Kumpulan Kawalan } \\
\text { (tradisional) }\end{array}$ \\
\hline $\begin{array}{l}\text { Skema diajar secara sistematik-isi } \\
\text { tersurat, persoalan, latar } \\
\text { masyarakat, perwatakan dan gaya } \\
\text { bahasa. }\end{array}$ & $\begin{array}{l}\text { Skema tidak diajar dengan } \\
\text { menggunakan model skema. Guru } \\
\text { memberi penerangan tentang } \\
\text { cerpen yang diajar. }\end{array}$ \\
\hline $\begin{array}{l}\text { Peranan guru sebagai pengurus } \\
\text { maklumat/ pengetahuan. }\end{array}$ & $\begin{array}{l}\text { Guru sebagai penyampai } \\
\text { maklumat }\end{array}$ \\
\hline $\begin{array}{l}\text { Aktiviti pengajaran lebih } \\
\text { berpusatkan pelajar. Pelajar } \\
\text { terlibat secara aktif. Pelajar } \\
\text { berbincang dengan menggunakan } \\
\text { skema sastera untuk mencari } \\
\text { jawapan bagi soalan-soalan } \\
\text { kefahaman. }\end{array}$ & $\begin{array}{l}\text { Aktiviti pengajaran lebih } \\
\text { berpusatkan guru. Penjelasan } \\
\text { diberikan oleh guru untuk } \\
\text { menjawab } \\
\text { kefahaman Polajar sobalan } \\
\text { pendengar pasif }\end{array}$ \\
\hline
\end{tabular}
Pelajar membentang hasil Pelajar mencatat nota. perbincangan. Guru bertindak sebagai fasilitator.

Aktiviti pengukuhan skema (secara lisan). Pelajar boleh Pelajar kurang berinteraksi dan menghasilkan beberapa contoh gaya bahasa yang terdapat dalam cerpen. Pelajar berinteraksi dan bertukar pendapat.

Pelajar dapat menganalisis manaPengetahuan pelajar hanya mana cerpen yang diberikan kepada mereka dengan kurang berbincang. menggunakan skema yang dipelajari 
daripada Kumpulan Eksperimen, guru ini tidak dilatih oleh pengkaji untuk mengajar dengan menggunakan model skema. Guru Kumpulan Kawalan bebas menggunakan pendekatannya sendiri (pendekatan tradisonal).

Selepas pengajaran selama enam minggu subjek Kumpulan Eksperimen dan Kumpulan Kawalan diberi Pascaujian dan kandungan ujian ini sama dengan Praujian. Selepas Pascaujian, pengkaji memberikan subjek Kumpulan Eksperimen soal selidik yang sama untuk mengetahui minat subjek terhadap cerpen selepas pengajaran dengan menggunakan model skema.

Tajuk-tajuk yang diajar kepada Kumpulan Eksperimen dan Kumpulan Kawalan selama enam minggu dijelaskan dalam Jadual 6. Bagi mendapatkan kesahan ujian, pengkaji memastikan tajuktajuk yang dipilih adalah bersesuaian dengan tahap kebolehan pelajar Tingkatan Empat.

Jadual 6. Senarai Tajuk Yang Diajar Mengikut Minggu

\begin{tabular}{|c|c|}
\hline Minggu & Tajuk \\
\hline 2 & $\begin{array}{l}\text { Budi Yang Tak Terbeli - aspek persoalan dan } \\
\text { latar masyarakat }\end{array}$ \\
\hline 3 & $\begin{array}{l}\text { Budi Yang Tak Terbeli - aspek gaya bahasa dan } \\
\text { perwatakan }\end{array}$ \\
\hline 4 & $\begin{array}{l}\text { Lambaian Malar Hijau - aspek persoalan dan } \\
\text { latar masyarakat }\end{array}$ \\
\hline 5 & $\begin{array}{l}\text { Lambaian Malar Hijau - aspek gaya bahasa dan } \\
\text { perwatakan }\end{array}$ \\
\hline 6 & $\begin{array}{l}\text { Menatap Wajahnya - aspek persoalan dan latar } \\
\text { masyarakat }\end{array}$ \\
\hline 7 & $\begin{array}{l}\text { Menatap Wajahnya - aspek gaya bahasa dan } \\
\text { perwatakan }\end{array}$ \\
\hline
\end{tabular}

\section{Alat Ukur}

Alat ukur yang digunakan dalam kajian ini ialah Praujian dan Pascaujian (kandungan kedua-dua ujian ini adalah sama), dan soal selidik tentang minat terhadap cerpen (KOMSAS Bahasa Melayu) 
Jadual 7. Kandungan Praujian/Pascaujian

\begin{tabular}{lccccccc}
\hline Petikan Cerpen & $\begin{array}{c}\text { Masa } \\
\text { (minit) }\end{array}$ & & Jenis Soalan & & $\begin{array}{c}\text { Jumlah } \\
\text { Soalan }\end{array}$ \\
\cline { 3 - 4 } & & & S P W L G & & \\
\hline Lambaian Malar Hijau & 40 & 2 & 1 & 1 & 1 & 1 & 6 \\
\hline Menatap Wajahnya & 40 & 2 & 1 & 1 & 1 & 1 & 6 \\
\hline Budi Yang Tak Terbeli & 40 & 2 & 1 & 1 & 1 & 1 & 6 \\
\hline
\end{tabular}

Nota: $\mathrm{S}=$ Tersurat, $\mathrm{P}=$ Persoalan, $\mathrm{W}=$ Perwatakan, $\mathrm{L}=$ Latar Masyarakat, $G=$ Gaya Bahasa

Dua orang guru mata pelajaran Bahasa Melayu yang terlatih dan mempunyai pengalaman melebihi lima tahun telah menyemak soalan-soalan Praujian/Pascaujian untuk memastikan soalan-soalan tersebut sesuai dengan kebolehan pelajar Tingkatan Empat. Jawapan dan pemberian markah untuk soalan tersurat, soalan tentang persoalan, soalan tentang perwatakan, soalan tentang latar masyarakat dan soalan tentang gaya bahasa juga disediakan oleh pengkaji setelah berbincang dengan dua orang guru tersebut untuk memastikan tahap soalan setaraf dengan kebolehan pelajar Tingkatan Empat. Guru tersebut tidak ada kaitan dengan subjek kajian.

Soal selidik tentang minat terhadap pembelajaran cerpen terdiri daripada 10 item berdasarkan skala Likert. Pengkaji telah mengadaptasi 10 item daripada soal selidik yang digunakan oleh Hazri Jamil (1998). Skor untuk setiap respons terhadap soal selidik diberi berdasarkan Skala Likert empat mata yang mempunyai julat nilai 1 hingga 4. Pencapaian pelajar bagi minat terhadap cerpen diperoleh dengan menjumlah mata setiap pelajar bagi 10 item tersebut.

\section{Kajian Rintis}

Satu kajian rintis dijalankan bagi kedua-dua instrumen (Praujian/ Pascaujian dan soal selidik) yang digunakan dalam kajian bagi mendapatkan kebolehpercayaannya. Kajian rintis ini bertujuan untuk melihat kesesuaian ujian dari segi kandungan, kesesuaian 
masa menjawab dan kejelasan arahan. Kajian rintis dijalankan ke atas 34 orang pelajar perempuan Tingkatan Empat di sebuah sekolah di Butterworth yang kebolehan akademik pelajar dan ciri-ciri sekolah hampir sama dengan Kumpulan Eksperimen dan Kumpulan Kawalan. Dapatan kajian rintis ini menunjukkan bahawa pelajar dapat memahami segala arahan dan kehendak soalan dalam Praujian/Pascaujian dan soal selidik. Masa yang diperuntukkan bagi Praujian/Pascaujian dan soal selidik juga didapati mencukupi bagi pelajar menjawab soalan-soalan tersebut. Nilai koefisyen kebolehpercayaan Cronbach's alpha bagi soal selidik tentang minat terhadap cerpen dalam kajian ini ialah 0.70.

Kertas jawapan pelajar bagi Praujian dan Pascaujian telah disemak oleh seorang guru Bahasa Melayu Tingkatan Empat yang terlatih dan berpengalaman (melebihi 5 tahun) dan guru tersebut tidak ada kaitan dengan subjek kajian.

\section{Analisis Data}

Ujian-t digunakan untuk membanding min pencapaian (gain score) Kumpulan Eksperimen dengan min pencapaian (gain score) Kumpulan Kawalan bagi setiap pemboleh ubah bersandar.

Markah beza antara Pascaujian dan Praujian (gain score) bagi setiap pemboleh ubah bersandar (pencapaian bagi keseluruhan soalan, pencapaian bagi soalan tersurat, soalan tentang tema dan persoalan, soalan tentang perwatakan, soalan tentang latar masyarakat dan soalan tentang gaya bahasa) bagi Kumpulan Eksperimen dan Kumpulan Kawalan telah diperoleh dengan menolak markah Praujian daripada markah Pascaujian. Markah gain score subjek digunakan sebagai markah pencapaian subjek untuk tujuan analisis data. Seterusnya Ujian-t (Independent Samples $T$ - test) dijalankan bagi menguji perbezaan min pencapaian.

Bagi pemboleh ubah bersandar minat (minat subjek Kumpulan Eksperimen terhadap cerpen) skor yang diperoleh bagi 10 item soal selidik dijumlahkan untuk mendapatkan skor minat subjek terhadap cerpen. Seterusnya, Ujian-t (Paired Samples T test) digunakan untuk memastikan sama ada terdapat perbezaan yang signifikan dalam minat subjek Kumpulan Eksperimen terhadap cerpen sebelum dan selepas pengajaran dengan menggunakan model skema. 


\section{DAPATAN}

Dapatan Ujian t dalam Jadual 8 jelas menunjukkan terdapat perbezaan yang signifikan antara pencapaian Kumpulan Eksperimen dan Kumpulan Kawalan bagi pencapaian keseluruhan soalan cerpen $(\mathrm{t}=22.35, \mathrm{df}=62, \mathrm{p}=0.000)$.

Jadual 8. Kesan pengajaran terbadap pencapaian bagi keseluruban soalan cerpen

$\begin{array}{lllll}\text { Kumpulan } & \text { N } & \begin{array}{l}\text { Min } \\ \text { Gain } \\ \text { Score }\end{array} & \begin{array}{c}\text { Min Gain } \\ \text { Score }\end{array} & \text { df } \\ & & & \end{array}$

\begin{tabular}{llllllll} 
Eksperimen & 32 & 18.50 & 3.67 & 16.84 & 22.35 & 62 & 0.000 \\
\cline { 1 - 4 } Kawalan & 32 & 1.66 & 2.16 & & & &
\end{tabular}

Tahap signifikan pada aras $\mathrm{p}<0.05$

Jadual 9. Kesan pengajaran terhadap pencapaian bagi soalan tersurat

\begin{tabular}{cccccc}
\hline Kumpulan & $\begin{array}{c}\text { Nin } \\
\text { Gain } \\
\text { Score }\end{array}$ & $\begin{array}{c}\text { SD } \\
\text { Score Gain } \\
\text { Score }\end{array}$ & & Nilai-t df & $p$ \\
& & &
\end{tabular}

\begin{tabular}{llllllll}
\hline Eksperimen & 32 & 0.03 & 0.31 & 0.16 & 1.52 & 62 & 0.134
\end{tabular}

Kawalan $\quad 32 \quad-0.13 \quad 0.49$

Tahap signifikan pada aras $\mathrm{p}<0.05$

Dapatan ini menunjukkan penggunaan model skema telah membantu subjek Kumpulan Eksperimen untuk mendapatkan pencapaian yang lebih tinggi dan signifikan berbanding dengan subjek Kumpulan Kawalan yang diajar dengan menggunakan pendekatan tradisional. Dapatan kajian juga menyokong dapatan Thang Siew Meng (1997), Davis dan Winek (1989) dan Subadrah Nair (2001), Sathiapathi (2004) dan Sundee (2005) yang menegaskan 
skema membantu dalam proses kefahaman bacaan, kerana subjek telah dilatih mengaktivasikan skema yang relevan untuk memahami aspek persoalan, perwatakan, latar masyarakat dan gaya bahasa dalam petikan yang dibaca. Jadual 9 menunjukkan perbezaan pencapaian bagi soalan tersurat.

Dapatan Ujian-t menjelaskan tidak terdapat perbezaan yang signifikan antara min subjek Kumpulan Eksperimen dengan min subjek Kumpulan Kawalan $(\mathrm{t}=1.52, \mathrm{df}=62, \mathrm{p}=0.134)$. Soalansoalan tersurat merupakan soalan yang mudah kerana jawapannya terdapat dalam teks. Oleh yang demikian, tidak terdapat perbezaan yang signifikan antara pencapaian subjek Kumpulan Eksperimen dengan Kumpulan Kawalan. Kajian yang dilakukan oleh Safiah Osman (1987) dan Thang Siew Meng (1997) menunjukkan skema lebih mempengaruhi pemahaman subjek bagi soalan-soalan yang melampaui teks iaitu soalan-soalan tersirat berbanding dengan soalan-soalan tersurat.

Dapatan Ujian-t (dalam Jadual 10) jelas mempamerkan terdapat perbezaan yang signifikan antara min subjek Kumpulan Eksperimen dengan min subjek Kumpulan Kawalan $(t=14.38, d f=62, p=0.000)$. Dapatan ini menunjukkan penggunaan model skema telah membantu subjek Kumpulan Eksperimen untuk mendapatkan pencapaian yang lebih tinggi dan signifikan bagi soalan tentang tema dan persoalan berbanding dengan subjek Kumpulan Kawalan yang diajar dengan menggunakan pendekatan tradisional.

Jadual 10. Kesan pengajaran terhadap pencapaian bagi soalan tentang persoalan

$\begin{array}{cccclll}\text { Kumpulan } & \mathbf{N} & \begin{array}{l}\text { Min } \\ \text { Gain } \\ \text { Score }\end{array} & \text { SD } & \begin{array}{c}\text { Perbezaan } \\ \text { Min Gain } \\ \text { Score }\end{array} & & \end{array}$

\begin{tabular}{llllllll}
\hline Eksperimen & 32 & 3.38 & 0.94 & 3.22 & 14.38 & 62 & 0.000
\end{tabular}

Kawalan $\quad 32 \quad 0.16 \quad 0.85$

Tahap signifikan pada aras $\mathrm{p}<0.05$

Dapatan kajian ini selari dengan dapatan Dimino, Gersten, Carnine, dan Blake (1990), dan Subadrah (2001) yang menunjukkan 
skema tema dan persoalan yang diajar secara terancang telah terbina dalam struktur kognitif subjek, dan seterusnya membantu subjek Kumpulan Eksperimen mengesan persoalan dalam cerpen dengan baik dan signifikan berbanding dengan subjek Kumpulan Kawalan.

Dapatan Ujian-t (dalam Jadual 11) jelas menunjukkan terdapat perbezaan yang signifikan antara min Kumpulan Eksperimen dengan min Kumpulan Kawalan $(\mathrm{t}=9.00, \mathrm{~d}=62, \mathrm{p}=0.000)$ bagi soalan tentang perwatakan.

Jadual 11. Kesan pengajaran terhadap pencapaian bagi soalan tentang perwatakan

\begin{tabular}{|c|c|c|c|c|c|c|c|}
\hline Kumpulan & & $\begin{array}{l}\text { Min } \\
\text { Gain } \\
\text { Score }\end{array}$ & SD & $\begin{array}{l}\text { Perbezaan } \\
\text { Min Gain } \\
\text { Score }\end{array}$ & Nilai-t & df & $\mathrm{p}$ \\
\hline Eksperimen & 32 & 3.22 & 1.64 & 3.19 & 9.00 & 62 & 0.000 \\
\hline Kawalan & 32 & 0.03 & 1.15 & & & & \\
\hline
\end{tabular}

Tahap signifikan pada aras $\mathrm{p}<0.05$

Dapatan kajian menunjukkan bagi soalan tentang perwatakan peningkatan min Kumpulan Eksperimen lebih tinggi dan signifikan daripada Kumpulan Kawalan. Ini menjelaskan pengajaran skema perwatakan secara terancang dengan menggunakan model skema dapat membantu pelajar menjawab soalan perwatakan dengan baik. Dapatan ini menyokong dapatan kajian Emery (1996), Dimino, Gersten, Carnine, dan Blake (1990) dan Subadrah (2001) yang menjelaskan skema tentang perwatakan yang diajar secara terancang dapat mengukuhkan skema perwatakan dalam kognitif pelajar. Seterusnya skema perwatakan ini diaktifkan oleh pelajar semasa mengesan perwatakan dalam cerpen.

Dapatan Ujian-t (dalam Jadual 12) jelas menunjukkan terdapat perbezaan yang signifikan antara min Kumpulan Eksperimen dengan min Kumpulan Kawalan. $(\mathrm{t}=10.727, \mathrm{df}=62$, $\mathrm{p}=0.000)$ bagi soalan tentang latar masyarakat. 
Jadual 12. Kesan pengajaran dengan menggunakan model skema terbadap pencapaian bagi soalan tentang latar masyarakat

\begin{tabular}{lccccccc}
\hline Kumpulan & $\begin{array}{c}\text { N Min } \\
\text { Gain } \\
\text { Score }\end{array}$ & $\begin{array}{c}\text { SD Perbezaan Nilai-t } \\
\text { Min Gain } \\
\text { Score }\end{array}$ & df & p \\
\hline Eksperimen & 32 & 3.72 & 1.4643 & 3.125 & 10.727 & 62 & 0.000 \\
\cline { 1 - 4 } Kawalan & 32 & 0.59 & 0.7560 & & & & \\
\hline
\end{tabular}

Tahap signifikan pada aras $\mathrm{p}<0.05$

Dapatan kajian menunjukkan bagi soalan tentang latar masyarakat peningkatan min Kumpulan Eksperimen lebih tinggi dan signifikan daripada Kumpulan Kawalan. Ini menjelaskan pengajaran skema latar masyarakat secara terancang dengan menggunakan model skema dapat membantu pelajar menjawab soalan latar masyarakat dengan berkesan.

Dapatan ini menyokong dapatan kajian Webster (2001) yang menunjukkan skema ciri-ciri masyarakat dapat membantu pelajar memahami cerita yang dibacanya. Dalam kajian ini pelajar Kumpulan Eksperimen telah dilatih mengesan latar masyarakat dalam cerpen dan skema tersebut telah dapat dibina oleh pelajar dalam struktur kognitif mereka. Seterusnya skema tersebut telah digunakan oleh pelajar untuk menjawab soalan tentang latar masyarakat.

Dapatan Ujian-t (dalam Jadual 13) jelas menunjukkan terdapat perbezaan yang signifikan antara min Kumpulan Eksperimen dengan min Kumpulan Kawalan $(\mathrm{t}=29.22, \mathrm{df}=62, \mathrm{p}=0.000)$ bagi soalan tentang perwatakan.

Jadual 13. Kesan pengajaran terbadap pencapaian bagi soalan tentang gaya bahasa

\begin{tabular}{|c|c|c|c|c|c|c|c|}
\hline Kumpulan & $\mathbf{N}$ & $\begin{array}{l}\text { Min } \\
\text { Gain } \\
\text { Score }\end{array}$ & SD & $\begin{array}{c}\text { Perbezaan } \\
\text { Min Gain } \\
\text { Score }\end{array}$ & Nilai-t & df & $\mathrm{p}$ \\
\hline Eksperimen & 32 & 7.28 & 1.22 & 7.000 & 29.22 & 62 & 0.000 \\
\hline Kawalan & 32 & 0.28 & 1.28 & & & & \\
\hline
\end{tabular}

Tahap signifikan pada aras $\mathrm{p}<0.05$ 
Dapatan kajian menjelaskan bagi soalan tentang gaya bahasa peningkatan min Kumpulan Eksperimen lebih tinggi dan signifikan daripada Kumpulan Kawalan. Ini menunjukkan pengajaran skema gaya bahasa secara terancang dengan menggunakan model skema dapat membantu pelajar menjawab soalan gaya bahasa dengan baik. Dapatan ini menyokong dapatan kajian Subadrah (2001) dan Sundee (2005) bahawa skema gaya bahasa dapat meningkatkan pemahaman pelajar tentang gaya bahasa dan skema tersebut telah diaktifkan oleh pelajar (Kumpulan Eksperimen) semasa menjawab soalan tentang gaya bahasa dalam cerpen.

Seperti yang dilihat dalam jadual 14, tidak terdapat perbezaan yang signifikan dari segi minat subjek Kumpulan Eksperimen terhadap pembelajaran cerpen sebelum dalam selepas pengajaran dengan menggunakan model skema.

Jadual 14. Kesan pengajaran terhadap minat subjek. Kumpulan Eksperimen.

\begin{tabular}{llllllll}
\hline Kumpulan & mm & ms & pm & sp & df & t & p \\
\hline Eksperimen & 18.69 & 36.03 & 17.34 & 2.13 & 31 & 45.97 & 0.000
\end{tabular}

Tahap signifikan adalah pada aras $\mathrm{p}<0.05$

Nota: $\mathrm{mm}=$ Min Sebelum Pengajaran dengan menggunakan Model Skema; $\mathrm{ms}=$ Min selepas Pengajaran dengan menggunakan Model Skema; $\mathrm{pm}=$ Peningkatan Min; $\mathrm{sp}=$ Sisihan Piawai

Peningkatan min subjek Kumpulan Eksperimen $(\mathrm{N}=32)$ selepas pengajaran dengan menggunakan model skema ialah sebanyak 17.34. Peningkatan min ini adalah signifikan $(t=45.96$, $\mathrm{df}=31, \mathrm{p}=0.000$ ).

Dapatan ini adalah sejajar dengan dapatan kajian yang telah dilakukan oleh Yahya Othman (2003) yang menunjukkan apabila guru menggunakan satu pendekatan yang melibatkan pelajar secara aktif untuk mengajar KOMSAS Bahasa Melayu maka minat pelajar terhadap pembelajaran dapat ditingkatkan. Dapatan ini juga selari dengan dapatan kajian Sundee (2005) yang menunjukkan model skema dapat meningkatkan minat pelajar tehadap pembelajaran sajak. 


\section{KESIMPULAN}

Kajian ini memberi beberapa implikasi terhadap pengajaran dan pembelajaran cerpen KOMSAS Bahasa Melayu Tingkatan Empat. Dapatan kajian ini menunjukkan pendekatan model skema dapat meningkatkan pemahaman pelajar terhadap cerpen. Skema yang dibina secara terancang dalam struktur kognitif pelajar telah diaktivasikan oleh pelajar semasa proses pemahaman cerpen dan skema tersebut telah membantu mereka menjawab keseluruhan soalan cerpen, soalan tentang persoalan, soalan tentang perwatakan, soalan tentang latar masyarakat dan soalan tentang gaya bahasa dengan lebih baik dan signifikan berbanding dengan pelajar Kumpulan Kawalan.

Selain itu, dapatan kajian ini juga menunjukkan penggunaan model skema dapat meningkatkan minat pelajar secara signifikan terhadap cerpen. Oleh yang demikian, guru-guru Bahasa Melayu boleh menggunakan model ini dalam pengajaran cerpen (KOMSAS Bahasa Melayu) kerana model ini bukan hanya membantu pelajar dalam pencapaian cerpen malah dapat meningkatkan minat subjek terhadap pembelajaran cerpen.

Aktiviti pembelajaran dalam model skema juga adalah lebih berpusatkan pelajar dan dapat melibatkan pelajar secara aktif selaras dengan kehendak KBSM. Dalam pendekatan model skema peranan guru ialah sebagai fasilitator. Skema cerpen yang dipelajari oleh pelajar secara terancang tidak hanya terhad kepada cerpen yang dikaji malah dapat digunakan oleh pelajar untuk mengesan persoalan, perwatakan, latar masyarakat dan gaya bahasa dalam mana-mana cerpen. Adalah dicadangkan agar guru-guru Bahasa Melayu dan bakal guru diberikan pendedahan dan dilatih menggunakan kaedah Model Skema sebagai satu altenatif untuk mengajar KOMSAS dengan berkesan.

\section{RUJUKAN}

Anderson, R.C. (1985). Role of readers schema in comprehension, learning and memory. Dalam Singer, H. \& Ruddell, R.B. (eds)(1985). Theoretical models and processes of Reading, Newark, Delaware: International Reading Association.

Anderson, J.R. (2000). Cognitive psychology and its implications. New York: Worth Publishers. 
Ausubel, D.P. (1963). The psychology of meaningful verbal learning New York: Grune \& Stratton Inc.

Bartlett, F. (1932). Remembering. London: Cambridge University Press.

Byrnes, J.P. (2001). Cognitive development and learning in instructional contexts (2nd Ed). Boston: Allyn \& Bacon.

Chai Moo Hong (1989). Effect of pre-reading instruction on the comprehension of reading comprehension in english among undergraduates. Unpublished Ph.D Thesis, University of Malaya, Kuala Lumpur.

Chervenick, E.C. (1992). Schema theory: Teaching US history to beginning amnesty students. Tesis sarjana yang tidak diterbitkan. Biola University. ERIC ED 354787.

Chiang, C.S. \& Dunkel, P. (1992). The effect of speech modification, prior knowledge and listening proficiency on EFL lecture learning, TESOL Quarterly, 26(2), 345-374.

Davis, S.J. \& Winek, J. (1989). Improving expository writing by increasing background knowledge. Journal of Reading, 33(3), 178-181.

Dimino, J., Gersten, R., Carnine, D. \& Blake, G. (1990). Story grammar: An approach for promoting at risk secondary students comprehension of literature. The Elementary School Journal, 91(1), 19-32.

Driscoll, M.P. (1994). Psychology of learning for instruction. Boston: Allyn and Bacon.

Durokhman Mohd Basri (2001). Polemik pembelajaran sastera berterusan dan cabaran KOMSAS wajar diatasi segera. Berita Harian, 15 Februari 2001.

Emery, D.W. (1996). Helping readers comprehend stories from the characters pespectives. The Reading Teacher, 49(7), 534-542.

Gagne, E.D., Yekovich, C.W. \& Yekovich, F.R. (1993). The Cognitive psychology of School Learning. New York: Harper Collins.

Hazri Jamil (1998). Kesan pendekatan secara penyebatian kemahiran berfikir kritis terhadap pembelajaran sajak Laporan Praktikum Sarjana Pendidikan, Pusat Pengajian Ilmu Pendidikan, Universiti Sains Malaysia.

Izzah Abdul Aziz (2000). Inovasi pengajaran kesusasteraan. Kertas kerja yang dibentangkan dalam Seminar Kebangsaan Teks Komponen Kesusasteraan Melayu dalam Mata Pelajaran Bahasa Melayu, Kuala Lumpur, 12-14 Julai 2000.

Kementerian Pendidikan Malaysia (1999). Sukatan pelajaran Bahasa Melayu KBSM (Edisi Penyesuaian). Kuala Lumpur: Pusat Perkembangan Kurikulum. 
Kant, I. (1963). Critique of pure reason. (Smith, N.K. trans.). London: Macmillan.

Lazar, G. (1993). Literature and language teaching: A guide for teachers and trainers. Victoria: Cambridge University Press.

Lembaga Peperiksaan Malaysia. (2001). Laporan Prestasi Sijil Pelajaran Malaysia, Kuala Lumpur: Kementerian Pendidikan Malaysia. http:/ /www.moe.gov.my/lp.htm. Diakses pada 25/11/2002.

Marohaini Yusof (1989). Strategi pengajaran bacaan dan kefahaman. Kuala Lumpur: Dewan Bahasa dan Pustaka.

Marohaini Yusof. (2001). Landasan pengajaran komponen sastera dalam bahasa melayu. Jurnal Dewan Bahasa, 1(6), 20-26.

Rahman Shaari (1990). Tanggapan bahan dan kaedah pengajaran sastera. Shah Alam: Marwilis Publisher.

Rumelhart, D.E. (1977). Understanding and summarising brief stories. Dalam Basic process in reading: peception and comprehension, Berge, D.L. \& Samuels, J. (eds.). New Jersey: Lawrence Erlbaum.

Rumelhart, D.E. (1980). Schemata: The building blocks of cognition. Dalam Spiro, R.J, Bruce, B.C \& Brewer, W.F. (Eds), Theoretical issues in reading comprehension (hlm.34-57). New Jersey: Lawrence Erlbaum.

Rumelhart, D.E. \& Norman, D. A. (1978). Acceretion, tuning and restructuring: Three models of learning, Dalam Semantic factors in cognition, oleh Anderson, R. C., Spiro, R. J. \& Montaque, W.E. (eds). Hillsdale, New Jersey: Lawrence Erlbaum.

Saedah Siraj (1992). Mengajar sastera: Teori, eksperimen, aplikasi. Kuala Lumpur: Pustaka Warisan.

Safiah Osman (1987). Schema theory and second language reading comprehension. Jurnal Pendidikan, 2, 55-65.

Sathiapathi M.K. Madhavan Nair (2004). Keberkesanan pendekatan skema terancang terhadap kefahaman bacaan sajak. (KOMSAS) Bahasa Melayu di kalangan murid-murid Tingkatan Empat. Laporan Praktikum Sarjana Pendidikan, Pusat Pengajian Ilmu Pendidikan, Universiti Sains Malaysia.

Schank, R.C. \& Abelson, R.P. (1977). Scripts, plans, goals and understanding. Hilldale, New Jersey: Lawrence Erlbaum Associates.

Singer, H. \& Donlan, D. (1985). Problem solving schema with question generation for omprehension of complex short stories, dalam Theoretical models and process of reading. Singer, H. \& Ruddell, R.B. (eds)(1985). Newark, Delaware: International Reading Association. 
Spiro, R.J. (1980). Schema theory \& reading comprehension: New directions. Technical Report No.191. ERIC ED 119662.

Subadrah Nair (2001). Keberkesanan skema terhadap kefahaman bacaan bahan sastera. Tesis Doktor Falsafah yang tidak diterbitkan. Universiti Sains Malaysia.

Sundee@Santhi Rajamanikam (2005). Kesan pendekatan model skema terbadap kefahaman sajak bahasa tamil di kalangan Pelajar Tingkatan Empat. Tesis Sarjana Sastera Pendidikan yang tidak diterbitkan. Pusat Pengajian Ilmu Pendidikan, Universiti Sains Malaysia.

Thang Siew Meng (1997). Induced content schema vs induced linguistic schema - which is more beneficial for malaysian ESL readers? RELC Journal, 28(2), 107-121.

Webster, W.J. (2001). Effects of ninth graders culture - specific schemata on responses to multi-cultural literature. Journal of Educational Research, 95(1), 12-29.

Yahya Othman (2003). Minat dan pencapaian pelajar terhadap komponen sastera dalam Bahasa Melayu. Prosiding seminar pengajaran dan pembelajaran KOMSAS. Pusat Pengajian Ilmu Pendidikan, Universiti Sains Malaysia. 


\section{LAMPIRAN A}

Berikut ialah contoh skema persoalan, skema latar masyarakat, skema perwatakan dan skema gaya bahasa yang diajar kepada pelajar (Kumpulan Eksperimen) secara terancang.

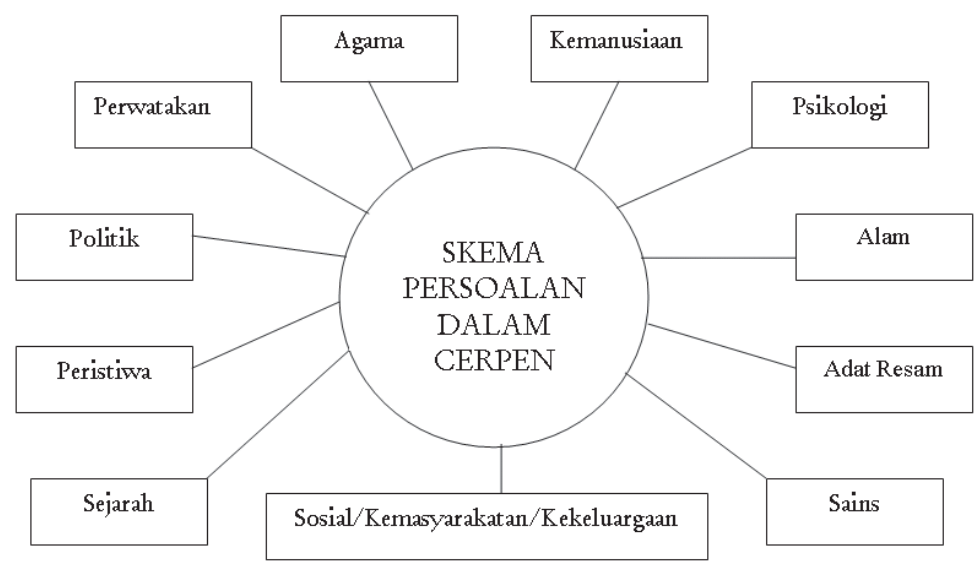

1) Skema persoalan dalam cerpen

Guru menjelaskan kepada pelajar cara mengesan persoalan dalam cerpen dengan melihat isu-isu yang dibincangkan dalam cerpen yang dikaji. Penjelasan guru disertakan dengan contoh dan dikaitkan dengan pengetahuan sedia ada pelajar. Guru memberikan contoh persoalan yang berkaitan dengan perwatakan, psikologi, peristiwa, adat resam, sosial/ kemasyarakatan/ kekeluargaan, politik, alam, agama, kemanusiaan, sains dan sejarah. Skema persoalan ini digunakan oleh pelajar untuk mengesan persoalan dalam cerpen. 


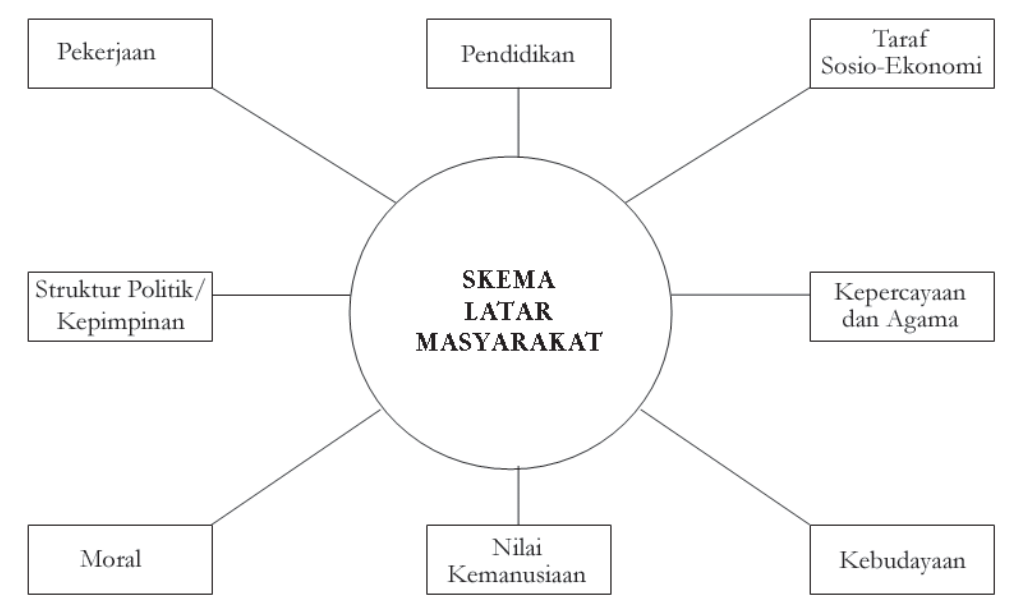

2) Skema latar masyarakat

Guru menjelaskan kepada pelajar bahawa latar masyarakat dalam cerpen boleh dikenal pasti oleh pelajar dengan melihat pekerjaan, taraf pendidikan, taraf sosio-ekonomi, kepercayaan dan agama, kebudayaan, nilai kemanusiaan, moral dan struktur politik/ kepimpinan masyarakat dalam cerpen yang dibaca. Penjelasan guru disertakan dengan contoh yang dikaitkan dengan pengalaman pelajar agar pelajar dapat membina skema yang jelas dan kukuh tentang latar masyarakat. Seterusnya skema latar masyarakat ini digunakan oleh pelajar untuk mengkaji latar masyarakat dalam cerpen yang dipelajari dalam kelas. 


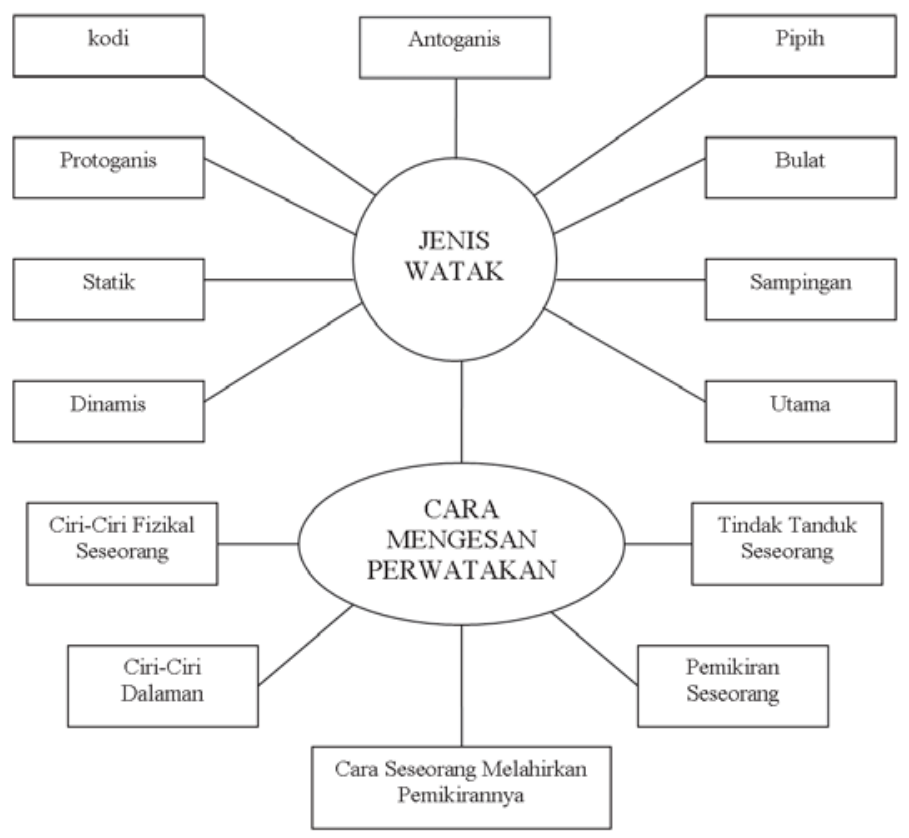

3) Skema watak dan perwatakan dalam cerpen

Guru menjelaskan kepada pelajar tentang jenis-jenis watak dengan memberikan contoh dan dikaitkan dengan pengalaman pelajar. Seterusnya guru menjelaskan kepada pelajar cara mengesan perwatakan seseorang watak iaitu melalui cirri-ciri fizikal seseorang, ciri-ciri dalaman seseorang, tidak-tanduk seseorang, pemikiran seseorang, dan cara seseorang itu melahirkan pemikirannya. Penjelasan guru disertakan dengan contoh dan dikaitkan dengan pengetahuan sedia ada pelajar. Skema perwatakan ini digunakan oleh pelajar untuk mengesan perwatakan watak-watak dalam cerpen yang dikaji dalam kelas. 


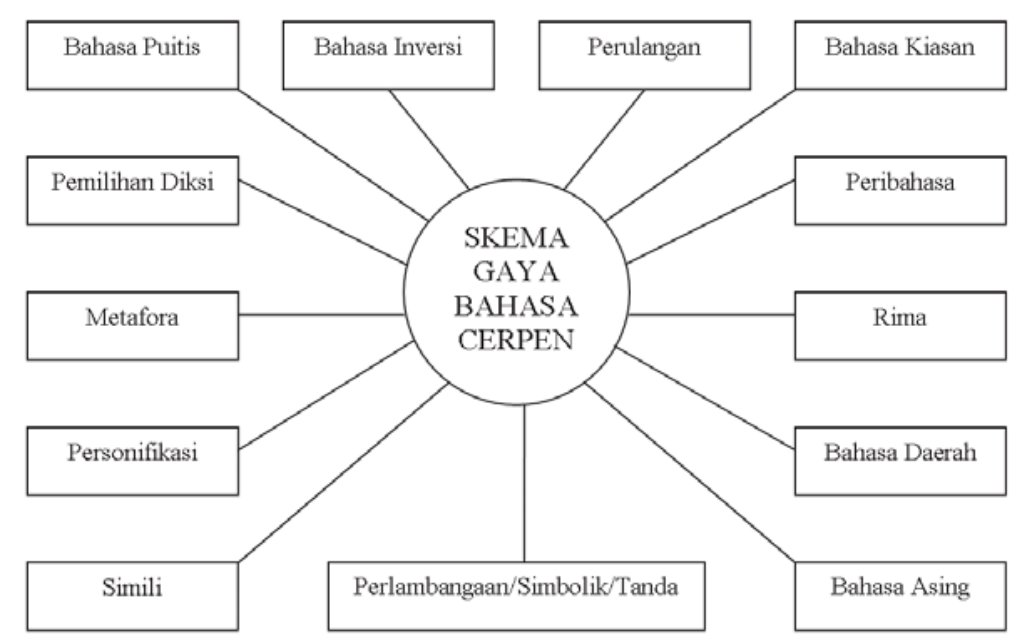

4) Skema gaya bahasa cerpen

Guru menjelaskan kepada pelajar gaya bahasa yang sering digunakan dalam cerpen. Penjelasan guru disertakan dengan contoh agar skema gaya bahasa dapat dibina dengan kukuh oleh pelajar dalam struktur kognitif mereka dan skema tersebut akan diaktifkan semasa mengesan gaya bahasa yang digunakan dalam cerpen yang dikaji. 